\title{
Transfer of intestinal bacterial components to mammary secretions in the cow
}

Wayne Young, Brad C Hine, Olivia A M Wallace, Megan M.R. Callaghan, Rodrigo Bibiloni

Results from large multicentre epidemiological studies suggest an association between the consumption of raw milk and a reduced incidence of allergy and asthma in children. Although the underlying mechanisms for this association are yet to be confirmed, researchers have investigated whether bacteria or bacterial components that naturally occur in cow's milk are responsible for modulating the immune system to reduce the risk of allergic diseases. Previous research in human and mice suggests that bacterial components derived from the maternal intestine are transported to breast milk through the bloodstream. The aim of our study was to assess whether a similar mechanism of bacterial trafficking could occur in the cow. Through the application of culture-independent methodology, we investigated the microbial composition and diversity of milk, blood and feces of healthy lactating cows. We found that a small number of bacterial OTUs belonging to the genera Ruminococcus and Bifidobacterium, and the Peptostreptococcaceae family were present in all three samples from the same individual animals. Although these results do not confirm the hypothesis that trafficking of intestinal bacteria into mammary secretions does occur in the cow, they support the existence of an endogenous enteromammary pathway for some bacterial components during lactation in the cow. Further research is required to define the specific mechanisms by which gut bacteria are transported into the mammary gland of the cow, and the health implications of such bacteria being present in milk. 
3 Transfer of intestinal bacterial components to mammary secretions in the cow

4

5 Wayne Young ${ }^{1}$, Brad C Hine ${ }^{2 *}$, Olivia AM Wallace ${ }^{2}$, Megan Callaghan², and Rodrigo Bibiloni ${ }^{1 \neq}$

6

7 '1Food Nutrition \& Health Team, Food \& Bio-based Products Group, AgResearch Grasslands,

8 Palmerston North, New Zealand; '2Dairy Foods Team, Food \& Bio-based Products Group,

9 AgResearch Ruakura, Hamilton, New Zealand.

10

$11 \neq$ Corresponding author: Rodrigo Bibiloni. Current address: Arla Strategic Innovation Centre

12 (ASIC), Cultures \& Fermentation Team, Rørdrumvej 2, DK-8220 Brabrand, Denmark. Tel:

13 +45 8746 5142; Email: rodrigo.bibiloni@arlafoods.com

14

$15{ }^{*}$ Current address: CSIRO Animal, Food \& Health Sciences, Armidale, NSW, 2350, Australia. 16

17

18

19 


\section{Introduction}

22 Epidemiological studies have shown that growing up on a farm is associated with a lower

23 risk of developing allergy (Braun-Fahrländer et al., 1999; Ehrenstein et al., 2000; Waser et al.,

24 2004; Alfvén et al., 2006; Mutius \& Vercelli, 2010) and that the consumption of raw milk is

25 strongly correlated with this effect (Perkin \& Strachan, 2006; Waser et al., 2007). The

26 commercialisation of fresh raw (unpasteurised) milk remains a controversial issue (Press

27 release, 2014; Astley, 2014), and although its consumption has been discouraged due to

28 potential health risks associated with pathogens (Allerberger et al., 2003), there is a growing

29 body of evidence suggesting that consumption of unprocessed milk decreases the risk of

30 asthma in children (Riedler et al., 2001; Loss et al., 2011). The mechanism for this effect is

31 not yet fully understood, but it may be related to bacteria or bacterial components in the milk

32 that modulate the immune system and which are modified during milk processing (Gehring et

33 al., 2008; Hodgkinson et al., 2014).

34 Although rural families generally skim or heat raw milk before consumption, this milk differs

35 in many aspects from commercially available milk. Whereas commercial milk is usually

36 homogenised and pasteurised, milk obtained from the farm for local consumption is not

37 processed in these ways, potentially resulting in a higher microbial load. Results from

38 PASTURE, a large global study examining the effects of farm and urban living on asthma and

39 allergy, showed no differences in endotoxin levels of raw farm and commercially processed

40 milk (Lluis et al., 2014); however, samples were not analysed for other bacterial components

41 or presence of viable organisms.

42 It has been reported that human breast milk is not completely sterile (Heikkilä \& Saris,

43 2003; Martín et al., 2003; Beasley \& Saris, 2004; Jiménez et al., 2008), and that bacterial 
44 components derived from the maternal intestine are transported to the lactating breast by

45 phagocytic cells in the blood (Pérez et al., 2007). This fascinating observation suggests that

46 milk acts as a source of natural inoculum provided by the mother for the breast-fed newborn

47 that programs the neonatal immune system to respond appropriately when challenged with

48 specific environmental and dietary bacterial antigens.

49 We hypothesise that a similar mechanism of bacterial trafficking from the intestinal tract to

50 the mammary gland, previously reported in lactating mothers, also occurs in the cow,

51 contributing to the bacterial components found in raw cow's milk and facilitating bacterial

52 imprinting of the neonatal immune system. The identification of bacteria or bacterial

53 components in unprocessed cow's milk thought to originate from the intestinal tract would

54 support this hypothesis. Therefore we investigated the microbial composition of feces, milk

55 leukocytes and blood leukocytes in lactating cows by pyrosequencing barcode-tagged $16 \mathrm{~S}$

56 rRNA amplicons to identify bacterial groups common to all three microbial pools. Bacterial

57 imprinting of the neonate via trafficking of gut bacteria into mammary secretions in the cow

58 may also contribute to the protective effects that consuming raw cow's milk has been shown

59 to have on development of allergy in children. An understanding of the mechanisms by which

60 gut bacteria in milk imprint the neonatal immune system may provide the foundation for new

61 strategies on how to shape the intestinal microbiota of the infant to aid in the prevention of

62 immune disorders.

63 


\section{Materials and methods}

66 Animals. All experimental procedures were approved by the Ruakura Animal Ethics

67 Committee, AgResearch, New Zealand (application \#12345). A total of 35 lactating cows

68 (Friesian, Jersey or Friesian $\times$ Jersey cross) located at the Tokanui Dairy Research farm

69 (Waikato, NZ) were screened for the presence of subclinical/clinical mastitis infection. Only

70 cows identified as having a low pooled quarter somatic cell count (SCC), defined as $<100,000$

71 cells $/ \mathrm{mL}$, at previous routine herd testing (conducted by Livestock Improvement Corporation,

72 Hamilton, NZ) were screened. As part of the screening procedure, individual quarter milk

73 samples were collected from all cows and subjected to a rapid mastitis test (Shoof

74 International Ltd., Cambridge, NZ) and somatic cell count. Those animals showing any signs

75 of subclinical or clinical mastitis (rapid mastitis test [RMT] score $>1$ [gel formation detected] or

76 SCC $>200,000$ cells $/ \mathrm{mL}$ ) in any quarter were not eligible for the study. A subset of 12 cows,

77 not showing signs of subclinical or clinical mastitis as defined above, were subsequently

78 randomly selected to participate in the study. These lactating cows (age: 2-4 years old; parity:

79 1-3) were 180 days in milk on average at the time samples were collected. Cows were on

80 twice-daily milking. Five (5) aged-matched non-lactating, non-pregnant cows of the same

81 breed and showing no signs of disease were selected as control animals for blood analysis.

82 All cows were grazing and fed on the feed pad.

83 Sample collection. Udders were thoroughly cleaned and disinfected with $70 \%$ ethanol and

84 methylated spirit-impregnated swabs (Meths Clear, Vetpak), paying particular attention to the

85 teat end by polishing the teat orifice with the swabs. Afterwards, a 14-gauge Teflon cannula

86 (Terumo Surflo) was inserted into the teat canal and connected to a sterile sample container

87 by a drip extension similar to that described by Vangroenweghe and colleagues 
88 (Vangroenweghe et al., 2001). The cannula had a bevelled edge which curled inwards to

89 minimise any potential damage to the teat canal. A total of $800 \mathrm{~mL}$ of milk was collected from

90 each cow and placed in the cold $\left(4^{\circ} \mathrm{C}\right)$ until transported chilled to the analytical laboratory in

91 Hamilton, NZ. Immediately following the removal of the cannula, each quarter was sprayed

92 with chlorhexidine teat spray (Teat X, Deosan). Somatic cell counts were performed

93 frequently after the study to check for intramammary infections caused by the sampling

94 procedure. Blood samples (approximately $450 \mathrm{~mL}$ ) were collected via jugular venepuncture

95 under local anaesthetic (lignocaine hydrochloride monohydrate 2\%, PhoenixPharm Ltd.) and

96 sedation (detomidine, Zoetis NZ Ltd.) into sterile blood collection bags (Fenwal Inc.)

97 containing citrate phosphate dextrose as anticoagulant and Adsol as a red cell nutrient

98 solution. The bags were placed in the cold $\left(4^{\circ} \mathrm{C}\right)$ and transported chilled to the analytical lab

99 in Fielding, NZ. Skin was disinfected with $70 \%$ ethanol before venepuncture. Fecal samples

100 were collected directly from the rectum of each animal with a gloved hand, placed into a

101 sterile container, and stored at $-80^{\circ} \mathrm{C}$ until further analysis in Palmerston North, NZ.

102 White blood cell separation from blood and milk samples. Milk somatic cells (MSCs)

103 were isolated as previously described (Daley et al., 1991). Briefly, milk was allowed to warm

104 to room temperature, and centrifuged in $200 \mathrm{ml}$ aliquots, at $250 \times \mathrm{g}$ for $30 \mathrm{~min}$. Milk cells were

105 then washed with $80 \mathrm{~mL}$ phosphate buffered saline [PBS] (Dulbecco A, Oxoid Ltd.) and

106 centrifuged again for $15 \mathrm{~min}$. Cells were then resuspended in $80 \mathrm{~mL}$ of PBS containing 100

$107 \mu \mathrm{g} / \mathrm{mL}$ gentamycin sulphate (Boehringer Ingelheim Bioproducts) for $10 \mathrm{~min}$ to kill extracellular

108 bacteria and in suspension. Following incubation, cell suspensions were spun for $10 \mathrm{~min}$, and

109 washed with $40 \mathrm{~mL}$ PBS. After another $10 \mathrm{~min}$ spin, cells were resuspended in $1 \mathrm{~mL}$ PBS,

110 and stored at $-80^{\circ} \mathrm{C}$ until processed for DNA extraction as described below. All steps were 
111 completed at room temperature in sterile conditions in a laminar flow cabinet appropriate for 112 cell culture work.

113 White blood cells (WBCs) were isolated as follows. Blood bags were centrifuged at $15^{\circ} \mathrm{C}$

114 at low speed $(2,000 \times g$ for 5 min with no brake applied). Plasma supernatant, buffy coat layer

115 and the upper layer of red cells were transferred to a platelet bag using a Fenwal plasma

116 extractor (Baxter Healthcare), and centrifuged again $(4,500 \times g$ for $7 \mathrm{~min})$. Supernatant was

117 again removed with the manual extractor and discarded leaving approximately $80 \mathrm{~mL}$ of

118 pelleted cells in a minimal volume of plasma in the bag. The centrifuged cellular pellets

119 containing WBCs were resuspended in the remaining plasma, treated with gentamycin as

120 described above, washed and processed for bacterial DNA extraction as described below.

121 Skin swabs. After disinfection with ethanol but before milk collection, each teat and a defined

122 area immediately around the teat were swabbed using Amies charcoal swabs (Raylab NZ

123 Ltd.), and plated on Columbia sheep blood agar and McConkey agar plates (Fort Richard

124 Laboratories Ltd.) to check for bacterial contamination. Plates were incubated at $37^{\circ} \mathrm{C}$ for 24

$125 \mathrm{~h}$ in aerobic conditions. One (1) Columbia sheep blood agar plate from each sample was also

126 incubated at $37^{\circ} \mathrm{C}$ for $48 \mathrm{~h}$ in anaerobic jars using an anaerobic GasPak generator (BBL

127 Becton Dickinson) for facultative anaerobes.

128 Bacterial DNA extraction. Total DNA was extracted from $200 \mathrm{mg}$ of fecal samples using

129 NucleoSpin Soil kits (Macherey-Nagel $\mathrm{GmbH}$ ) according to manufacturer's instructions, but

130 with the following modification. Fecal samples were diluted in $700 \mu \mathrm{L}$ of NucleoSpin lysis

131 buffer SL2 and $150 \mu \mathrm{L}$ SX buffer, and homogenised using a FastPrep FP120 Cell Disrupter

132 (Qbiogene Inc.) set to speed 6.5 for $45 \mathrm{sec}$ prior to column purification of DNA. Milk and blood 
133 cells were pelleted by centrifugation and DNA extracted from the cell pellets using the same 134 method described for fecal samples.

135 High-throughput sequencing. Isolated DNA was then used to amplify the V3-V5 regions of 13616 S ribosomal DNA, with universal bacterial primers (Claus et al., 2011) containing GS FLX 137 adapter sequences, a unique 8 nucleotide 'barcode', and template specific sequences;

138 forward primer

139 5'-CGTATCGCCTCCCTCGCGCCATCAGNNNNNNNNAGGCCAGCAGCCGCGGTAA-3', 140 and reverse primer

141 5'-CTATGCGCCTTGCCAGCCCGCTCAGGCCRRCACGAGCTGACGAC-3', with 'N' 142 indicating barcode nucleotides. Amplification reactions were completed on a MasterCycler 143 ProS thermocycler (Eppendorf AG). Fecal DNA was amplified using the following conditions; $14495{ }^{\circ} \mathrm{C}$ for $4 \mathrm{~min}, 25 \mathrm{cycles}$ of $\left[95^{\circ} \mathrm{C}\right.$ for $30 \mathrm{sec} ; 49^{\circ} \mathrm{C}$ for $30 \mathrm{sec} ; 72^{\circ} \mathrm{C}$ for $60 \mathrm{sec}$ ] and $72{ }^{\circ} \mathrm{C}$ 145 for 7 min. The PCR product size was 604 base pairs. Milk and blood cell DNA was amplified 146 using the following PCR conditions; $95^{\circ} \mathrm{C}$ for $4 \mathrm{~min}, 40$ cycles of $\left[95^{\circ} \mathrm{C}\right.$ for $30 \mathrm{sec} ; 49{ }^{\circ} \mathrm{C}$ for $14730 \mathrm{sec} ; 72{ }^{\circ} \mathrm{C}$ for $60 \mathrm{sec}$ ] and $72{ }^{\circ} \mathrm{C}$ for 7 min. Several dilutions of template DNA were made if 148 the presence of PCR inhibitors was suspected. Samples were pooled and sent to the 149 commercial sequencing facility (Macrogen Inc., Seoul, South Korea). To control for 150 environmental contamination resulting from PCR with universal bacterial primers and high 151 cycle numbers (40), negative controls without template DNA were also sequenced.

152 Sequence analysis. Sequences were processed using QIIME 1.7. Reads were quality 153 filtered (quality score window $>50$ ) and assigned to corresponding samples according to 154 barcode sequences using default values for minimum/maximum allowable length of read 155 (200/1000), allowed number of ambiguous reads (6), and allowable homopolymer length (6) 156 (split_libaries.py -w 50 -b 8 -g - $r$-f). The resulting demultiplexed sequences were denoised 
157 and chimera checked using the Greengenes alignment as a database (release GG_13_5).

158 Sequences identified as chimeric were removed from subsequent analyses. Sequences

159 showing $97 \%$ or greater similarity were clustered into operational taxonomic units (OTUs)

160 using the UCLUST method. Representative sequences were assigned taxonomies using the

161 rdp method against the Greengenes GG_13_5 database (default 0.8 confidence threshold).

162 Alpha diversity and OTU networks were generated using QIIME 1.7. Hierarchical clustering

163 analysis of bacterial profiles was performed in R 3.0.2 (R Core Team, 2013) using Euclidean

164 distances and complete linkage clustering.

165 Quantitative PCR. Bacterial DNA was amplified by quantitative PCR (qPCR) with the

166 bacterial 16S rRNA gene primers F_Bact 1369 (5'-CGG TGA ATA CGT TCC CGG-3') and

167 R_Prok1492 (5'-TAC GGC TAC CTT GTT ACG ACT T-3') (Suzuki, Taylor \& DeLong, 2000),

168 using a Rotor-gene 6000 thermocycler (Qiagen). Samples were measured in duplicate using

$16910 \mu \mathrm{L}$ reactions consisting of $1 \mu \mathrm{L}$ DNA template, $0.25 \mu \mathrm{L}$ forward primer ( $10 \mathrm{pmol} / \mu \mathrm{L}), 0.25$

$170 \mu \mathrm{L}$ reverse primer (10 pmol/ $\mu \mathrm{L}), 3.5 \mu \mathrm{L}$ nuclease-free water, and $5 \mu \mathrm{L}$ of KAPA SYBR® FAST

171 Universal 2X qPCR Master Mix. Cycling conditions consisted of $95^{\circ} \mathrm{C}$ for $3 \mathrm{~min}$, followed by

17240 cycles of $\left[95^{\circ} \mathrm{C}\right.$ for $20 \mathrm{sec}, 60^{\circ} \mathrm{C}$ for $30 \mathrm{sec}$, and $72{ }^{\circ} \mathrm{C}$ for $30 \mathrm{sec}$. Calculated

173 concentrations $(\mathrm{ng} / \mu \mathrm{L})$ were normalized to extracted DNA concentrations. The amount of

174 DNA detected was expressed as equivalent number of Escherichia coli genomes per ng of

175 total DNA to provide an estimate of the numbers of bacteria present.

176 Statistical analyses. Ninety five percent confidence intervals for bacterial DNA quantities

177 were obtained using R version 3.0.2 (R Core Team, 2013). Significance of differences

178 between mean DNA concentrations was determined using the non-parametric Kruskal-Wallis

179 analysis of variance in $\mathrm{R}$, with $P$ values $<0.05$ deemed to be significant. Power analysis 
180 indicated that results from 5 non-lactating, non-pregnant control cows, and at least 10

181 lactating cows would detect a difference of 0 vs. $65 \%$ at the $5 \%$ significance level with $80 \%$

182 power, with each cow categorised on whether it shows trafficking (whether at least one OTU

183 is present in all three compartments [feces, blood and milk]) or not.

184 
186 Results

187 Amplification and sequencing of bacterial DNA from the three biological pools.

188 Bacterial DNA originating from MSCs and WBCs proved difficult to amplify using traditional

189 PCR conditions involving 25-30 cycles, probably due to its low abundance; thus, we 190 increased the number of PCR cycles to 40 . This practice, however, might lead to false 191 positive results. Therefore, we sequenced the negative controls (no DNA template), and 192 filtered the sequenced samples to exclude the OTUs found in these control samples.

193 A total of 190245 quality-checked bacterial 16S rRNA gene sequences were obtained by 194 pyrosequencing from all tested animals $(\min =1276, \max =25175 ;$ median $=4369)$. The 195 mean number ( \pm SEM) of sequences obtained from feces $(n=11)$, MSCs $(n=12)$, and WBCs $(n=11)$ was $8062 \pm 2097,4164 \pm 510$ and $3765 \pm 653$, respectively. The mean read 197 length was $281 \mathrm{bp}(\min =200 ; \max =564)$. The number of operational taxonomic units 198 (OTUs) at 97\% similarity were $2163(\min =16 ; \max =983 ;$ median $=262)$, excluding all OTUs 199 and sequences found in the negative control sample (15 OTUs).

200 Quantitative PCR analysis showed that mean amounts of bacterial DNA present per ng of 201 DNA extracted from MSCs $\left(6.51 \times 10^{-3} \mathrm{pg}\left[95 \% \mathrm{Cl}, 2.87 \times 10^{-3}\right.\right.$ to $\left.\left.1.02 \times 10^{-2} \mathrm{pg}\right]\right)$ were higher 202 than from WBCs $\left(1.79 \times 10^{-3} \mathrm{pg}\left[95 \% \mathrm{Cl}, 9.07 \times 10^{-4}\right.\right.$ to $\left.\left.2.66 \times 10^{-3} \mathrm{pg}\right]\right)$, which indicates 203 higher numbers of bacteria present in MSCs compared to WBCs.

204 No bacterial DNA was recovered from blood originating from the aged-matched, non205 lactating, non-pregnant control animals. Skin swabs collected from the teats after cleaning, 206 but before milk collection did not show signs of viable bacteria in the culture conditions 207 employed, ruling out any direct bacterial contamination from the skin during milk collection. 
208 Microbial composition of the three biological pools. Analysis of DNA extracted from

209 MSCs, WBCs and feces uncovered a small number of OTUs that were observed in all three

210 biological samples from at least one cow (Table 1). Sequence assignment to the closest

211 related taxa using the Greengenes GG_13_5 database indicated that sequences classified as

212 Ruminococcus genus, Peptostreptococcaceae family, and Bifidobacterium genus were found

213 concurrently in all three biological samples in a total of five, five and four cows, respectively.

214 Members of 15 bacterial phyla were detected in the WBCs, whereas 22 bacterial phyla were

215 represented in the MSCs. In comparison, fecal DNA contained representatives from only 13

216 phyla despite having the highest overall diversity at the 0.97 OTU level.

217 The microbial diversity of each environment, as shown by the mean Chao1 index \pm SEM at

218 a sampling depth of 1095 sequences was $596 \pm 17,427 \pm 59$ and $107 \pm 20$ for feces, MSCs

219 and WBCs respectively (Figure 1). As expected, fecal samples had greater microbial diversity

220 compared to blood and milk samples $(P<0.01)$. MSCs also had significantly greater microbial

221 diversity than WBCs $(P<0.01)$.

222 The profile of microbial sequences identified in the feces, MSCs and WBCs differed

223 between the sampling sites as shown by the hierarchical cluster analysis of bacterial profiles

224 (Figure 2). The most prevalent bacterial groups detected in the feces included, as expected,

225 members of the Firmicutes $(F)$ and Bacteroidetes $(B)$. In contrast, bacterial sequences in

226 WBCs were predominantly from Mycoplasma (33.9\%) and Streptophyta (24.1\%). Bacterial

227 profiles from milk more closely resembled that from feces (Figures 2-4), with the most

228 abundant groups including Staphylococcus (27.6\%), Ruminococcus (7.2\%),

229 Peptostreptococcaceae (6.5\%), Bifidobacterium (5.6\%), Butyrivibrio (2.3\%) (Table 2). 


\section{Discussion and Conclusion}

233 The general convention dictates that mammalian milk, including that of human and bovine 234 origin, is at its origin free from microorganisms. According to the Food and Agriculture

235 Organization of the United Nations, milk secreted into a cow's udder is sterile (FAO, 1990).

236 This theory, however, has been recently challenged. A few scientific studies using nucleic

237 acid-based methodologies have started to reveal that colostrum and human breast milk

238 contain microorganisms (Martín et al., 2003; Beasley \& Saris, 2004; Pérez et al., 2007),

239 becoming potential sources of bacterial exposure for the breast-fed newborn. Nevertheless,

240 the origin of such microorganisms, as well as their health implications, are still a controversial

241 issue. Although it is generally accepted that the presence of bacteria in milk can result from

242 contamination with bacteria from the mother's skin or the infant's mouth, a newly proposed

243 endogenous pathway to explain the origin of some milk bacteria is under debate. An entero-

244 mammary pathway has been suggested by which selected bacteria from the maternal

245 gastrointestinal microbiota reach the mammary secretions via the blood leukocytes (Martín et

246 al., 2004; Pérez et al., 2007; Fernández et al., 2013; Rodríguez, 2014). We hypothesised that

247 a similar mechanism of bacterial trafficking from the intestinal tract to the mammary gland,

248 previously reported in lactating mothers and mice, also occurs in the cow, contributing to the

249 bacterial components found in raw cow's milk. Although our findings do not definitely prove

250 our hypothesis, the presence of bacterial fragments in all three environments provides

251 support for the occurrence of a trafficking mechanism of bacterial components from the

252 intestinal tract to the mammary gland in the cow. Bearing in mind that the lactational

253 physiology of humans and rodents is different to that of ruminants, the occurrence of this 
254 endogenous bacterial circulation would lead to new scientific insights of bovine lactation 255 physiology.

256 We employed an established culture-independent methodology to investigate the bacterial 257 composition in the three biological compartments. Our results suggest that there are bacterial 258 components belonging to the Ruminococcus genus, the Peptostreptococcaceae family, and 259 the Bifidobacterium genus that can be found in common in feces, WBCs and MSCs from the 260 same lactating cow. It is therefore reasonable to speculate that members of these bacterial 261 groups may have been transferred from the gut to the mammary gland via circulating white 262 blood cells. Pérez and colleagues observed DNA from Bifidobacterium longum in milk 263 samples from lactating mothers which was also present in their blood and feces (Pérez et al., 264 2007). These researchers also found sequences from Bacteroides, Clostridium, and

265 Eubacterium in human milk. Martín et al. have also isolated bifidobacterial species in human 266 milk (Martín et al., 2003).

267 Two aspects in our approach require attention: namely, milk collection and PCR 268 amplification. Common practise for milk sampling from cows is by hand stripping. When hand269 stripping, it is very difficult to collect milk aseptically due to skin flakes, dust, and hair in the 270 environment, which can all introduce bacterial contamination to the sample. Rather than 271 hand-stripping, we used a catheter inserted into the teat canal which was connected to the 272 sample container by a drip extension set that allowed milk collection by gravity. This 273 procedure not only prevented the teat canal from being stretched or damaged (historical post274 sampling SCC records suggest no intramammary infections were caused by the procedure, 275 data not shown), but also avoided external microbial contamination of the milk. Although we 276 cannot exclude that bacteria of skin origin or from the keratin lining could have colonised the 277 milk duct of the cow's udders and then transferred to the milk, we have designed our 
278 experiment to exclude any bacteria in suspension by collecting only white cells (the majority

279 of the somatic cells in blood) by centrifugation. Additionally, these cells were treated with the

280 bactericidal gentamycin, and consequently only internalised bacterial signatures or those

281 coming from membrane bound bacteria were measured by high throughput sequencing.

282 Finally, the three laboratories located in different sites each processed only one type of the

283 three biological samples [feces, blood and milk] which significantly reduces the possibility of

284 introducing the same type of contamination to each of the samples.

285 Although environmental contaminants can become disproportionately represented when

286 amplifying sequences from samples containing low copy numbers of bacterial DNA compared

287 to non-target DNA, our results show that high-throughput sequencing is a useful method for

288 assessing microbial composition in milk and blood. Despite the presence of contaminant

289 sequence in the negative control samples subjected to 40 rounds of PCR amplification, the

290 number of OTUs observed was substantially lower than that in blood and milk samples. Taxa

291 found in common in all three environments were identified in a maximum of 5 cows out of the

292 total tested animals. The variation in the number of taxa found in our study could be perhaps

293 related to the stage of lactation, days in milk, or it could simply be from chance. Because we

294 amplified very small quantities of bacterial DNA in the blood and milk, it may be also possible

295 that bacterial species of interest present in some samples were not detected. Laser capture

296 microdissection in combination with direct-captured cell PCR has recently been developed to

297 identify microbial contaminants in milk, potentially representing a suitable tool to detect

298 bacterial species present in low abundance (Bracke et al., 2014). Quantitative PCR analysis

299 showed higher numbers of bacteria present in MSCs compared to WBCs, suggesting that

300 cells with bacteria accumulated in the mammary gland as there were more bacteria per unit of

301 mammalian DNA in the milk than there was in the blood. 
302 Milk sample collection techniques and cell differentiation methodologies can influence milk

303 cell differentiation results; however, it is generally accepted that macrophages are the

304 predominant cell type in bovine milk from healthy glands (Miller, Paape \& Fulton, 1991;

305 Dosogne et al., 2003). Lymphocytes and neutrophils are also present along with a small

306 percentage of detached epithelial cells which together make up the total somatic cell

307 population. During inflammation, neutrophils are rapidly recruited to the mammary gland,

308 becoming the predominant cell type and increasing somatic cell counts in inflamed quarters

309 (Riollet, Rainard \& Poutrel, 2000). It is noteworthy that although the methods used to screen

310 cows for suitability to be used in the study suggested that selected animals were not

311 harbouring an intramammary infection at the time of sampling, bacteriology analysis of

312 quarter milk samples was not undertaken to confirm the absence of subclinical mastitis during

313 the screening procedure. Nevertheless, the phagocytic macrophages were expected to be the

314 predominant cell type present in milk from these animals. Macrophages in milk are thought to

315 be derived from blood monocytes which exit the bloodstream, migrate across the epithelium

316 and enter the mammary gland (Goldman \& Goldblum, 1997). Macrophages play a key role in

317 immune surveillance, acting as scavenger cells with the ability to recognise pathogens and

318 initiate innate responses through the secretion of pro-inflammatory mediators. Following

319 phagocytosis of antigens, some tissue macrophages differentiate into dendritic cells and

320 migrate to draining lymph nodes where they interact with T-cells to induce antigen-specific

321 acquired responses (Randolph et al., 1999). Macrophages can also function as antigen

322 presenting cells, a subset of which are able to induce oral tolerance through interaction with

$323 \mathrm{CD}_{103^{+}}$dendritic cells (Mazzini et al., 2014). Breast milk macrophages express certain

324 dendritic cell surface markers, spontaneously produce granulocyte-macrophage colony-

325 stimulating factor and have the unique ability to differentiate into dendritic cells when 
326 stimulated with interleukin-4 (Ichikawa et al., 2003). Combined, these findings suggest that

327 breast milk macrophages exhibit characteristics consistent with that of partially differentiated

328 dendritic cells, and that such cells may play a role in mediating T-cell dependant immune

329 responses in the mammary gland. However, as the enhanced functionality displayed by milk

330 macrophages is thought to be induced by phagocytosis of milk components following entry to

331 the mammary gland, such findings do not provide an explanation as to the likely mechanisms

332 by which gut bacteria and bacterial components are transported from the intestinal lumen to

333 the mammary gland. The recirculation of lymphocytes between distant mucosal sites via the

334 blood and lymphatic systems has been studied in several species. In humans and rodents,

335 lymphoid cells in gut-associated lymphoid tissue (GALT) home to the mammary gland forming

336 an entero-mammary link and contributing to what has been termed the 'common mucosal

337 system' in which distant mucosal sites are linked via the migration of immune cells (Roux et

338 al. 1977; Weisz-Carrington et al. 1979). In contrast to these findings, studies in cattle have

339 demonstrated that migration of lymphoid cells between the gut and the mammary gland is

340 limited, suggesting that the entero-mammary link is less functional in ruminants (Harp et al.

341 1988). More recently it has been proposed that although the mononuclear phagocytes found

342 in breast milk are largely derived from peripheral blood monocytes, a proportion of these

343 mononuclear phagocytes are dendritic cell-like cells which arise in gut-associated lymphoid

344 tissue, capture luminal microbiota and then transport these microbial components to the

345 mammary gland. Such a mechanism is thought to exist to educate the neonatal immune

346 system to recognise commensal-associated molecular patterns of bacteria and to respond to

347 such bacteria appropriately (Donnet-Hughes et al., 2010). To the authors knowledge the role

348 of dendritic cells in trafficking bacterial components from the gut to the mammary gland in

349 ruminants remains relatively unknown. 
350 The possibility of bacterial trafficking from the gut to the mammary gland in the cow opens

351 up interesting alternatives for probiotic use in the manipulation of the intestinal ecosystem for

352 animal health. Ingested probiotics with the ability to get access to the mammary gland

353 through the bloodstream could be employed to combat pathogenic microorganisms involved

354 in the development of mastitis. Finally, further research is required to unequivocally link the

355 biological activity of bacterial groups of interest in the development of allergy, in which case

356 technological strategies in milk processing could be directed towards maintaining the integrity

357 of such beneficial components.

361 Acknowledgements

362 The authors would like to thank Laura Mayal, Allison Cullum, and Taisekwa Chikazhe for 363 their assistance with sampling at the farm, Harold Henderson for statistical advice, and Julie 364 Cakebread, Henning Seedorf and lan Colditz for reviewing the manuscript.

\section{References}

370 Alfvén T, Braun-Fahrländer C, Brunekreef B, von Mutius E, Riedler J, Scheynius A, van

371 Hage M, Wickman M, Benz MR, Budde J, Michels KB, Schram D, Üblagger E, Waser M,

372 Pershagen G, PARSIFAL study group. 2006. Allergic diseases and atopic sensitization in 
373 children related to farming and anthroposophic lifestyle: the PARSIFAL study. Allergy 61:414374421.

375 Allerberger F, Friedrich AW, Grif K, Dierich MP, Dornbusch HJ, Mache CJ, Nachbaur E, 376 Freilinger M, Rieck P, Wagner M, Wagner M, Caprioli A, Karch H, Zimmerhackl LB. 2003.

377 Hemolytic-uremic syndrome associated with enterohemorrhagic Escherichia coli O26:H 378 infection and consumption of unpasteurized cow's milk. International Journal of Infectious 379 Diseases 7:42-45.

380 Astley M. 2014. Raw milk rule change will increase risk of illness: IDFA, NMPF 2014

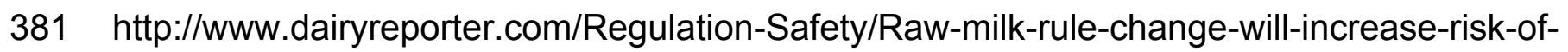
382 illness-IDFA-NMPF.

383 Beasley SS, Saris PEJ. 2004. Nisin-producing Lactococcus lactis strains isolated from 384 human milk. Applied and Environmental Microbiology 70:5051-5053.

385 Bracke N, Van Poucke M, Baert B, Wynendaele E, De Bels L, Van Den Broeck W, 386 Peelman L, Burvenich C, De Spiegeleer B. 2014. Identification of a microscopically selected 387 microorganism in milk samples. Journal of Dairy Science 97: 609-615.

388 Braun-Fahrländer C, Gassner M, Grize L, Neu U, Sennhauser FH, Varonier HS, Vuille JC, 389 Wuthrich B. 1999. Prevalence of hay fever and allergic sensitization in farmer's children and 390 their peers living in the same rural community. Clinical and Experimental Allergy 29:28-34.

391 Claus SP, Ellero SL, Berger B, Krause L, Bruttin A, Molina J, Paris A, Want EJ, de Waziers 392 I, Cloarec O, Richards SE, Wang Y, Dumas ME, Ross A, Rezzi S, Kochhar S, Van Bladeren

393 P, Lindon JC, Holmes E, Nicholson JK. 2011. Colonization-induced host-gut microbial 394 metabolic interaction. MBio 2:e00271-10. 
Daley ER, Oldham ER, Williams TJ, Coyle PA. 1991. Quantitative and qualitative

396

properties of host PMN cells during experimentally induced Staphylococcus aureus mastitis in cows. American Journal of Veterinary Research 52: 74-479.

Donnet-Hughes A, Pérez PF, Doré J, Leclerc M, Levenez F, Benyacoub J, Serrant P, Segura-Roggero I, Schiffrin EJ. 2010. Prebiotics and probiotics usefulness against pathologies - Potential role of the intestinal microbiota of the mother in neonatal immune education. Proceedings of the Nutrition Society 69: 407-415.

Dosogne H, Vangroenweghe F, Mehrzad J, Massart-Leën AM, Burvenich C. 2003.

Differential leukocyte count method for bovine low somatic cell count milk. Journal of Dairy Science 86: 828-34.

Ehrenstein OS, von Mutius E, Illi S, Baumann L, Böhm O, von Kries R. 2000. Reduced risk of hay fever and asthma among children of farmers. Clinical and Experimental Allergy 30:187-193.

Fernández L, Langa S, Martín V, Maldonado A, Jiménez E, Martín R, Rodríguez JM. 2013. The human milk microbiota: Origin and potential roles in health and disease. Pharmacological Research 69: 1-10.

Food and Agriculture Organization of the United Nations. 1990. Milking, Milk Production Hygiene and Udder Health. FAO Animal Production \& Health Paper (www.fao.org).

Gehring U, Spithoven J, Schmid S, Bitter S, Braun-Fahrländer C, Dalphin JC, Hyvarinen A, Pekkanen J, Riedler J, Weiland SK, Büchele G, von Mutius E, Vuitton DA, Brunekreef B;

PASTURE study group. 2008. Endotoxin levels in milk samples from farming and non-farming families - the pasture study. Environment International 34: 1132-1136.

Goldman AS, Goldblum RM. 1997. Transfer of maternal leukocytes to the infant by human milk. Current Topics in Microbiology and Immunology 222: 205-213. 
419 Harp JA, Runnels PL, Pesch BA.1988. Lymphocyte recirculation in cattle: Patterns of 420 localization by mammary and mesenteric lymph node lymphocytes. Veterinary Immunology 421 and Immunopathology 20:31-39.

422 Heikkilä MP, Saris PEJ. 2003. Inhibition of Staphylococcus aureus by the commensal 423 bacteria of human milk. Journal of Applied Microbiology 95:471-478.

424 Hodgkinson AJ, McDonald NA; Hine B. 2014. Effect of raw milk on allergic responses in a 425 murine model of gastrointestinal allergy. British Journal of Nutrition 112: 390-397.

426 Ichikawa M, Sugita M, Takahashi M, Satomi M, Takeshita T, Araki T, Takahashi H. 2003.

427 Breast milk macrophages spontaneously produce granulocyte-macrophage colony-

428 stimulating factor and differentiate into dendritic cells in the presence of exogenous

429 interleukin-4 alone. Immunology 108: 189-195.

430 Jiménez E, Delgado S, Maldonado A, Arroyo R, Albújar M, García N, Jariod M, Fernández 431 L, Gómez A, Rodríguez JM. 2008. Staphylococcus epidermidis: a differential trait of the fecal 432 microbiota of breast-fed infants. BMC Microbiology 8:143.

433 Lluis A, Depner M, Gaugler B, Saas P, Casaca VI, Raedler D, Michel S, Tost J, Liu J, 434 Genuneit J, Pfefferle P, Roponen M, Weber J, Braun-Fahrländer C, Riedler J, Lauener R, 435 Vuitton DA, Dalphin JC, Pekkanen J, von Mutius E, Schaub B; Protection Against Allergy: 436 Study in Rural Environments Study Group. 2014. Increased regulatory T-cell numbers are 437 associated with farm milk exposure and lower atopic sensitization and asthma in childhood. 438 Journal of Allergy and Clinical Immunology 133:551-559.

439 Loss G, Apprich S, Waser M, Kneifel W, Genuneit J, Büchele G, Weber J, Sozanska B, 440 Danielewicz H, Horak E, van Neerven RJ, Heederik D, Lorenzen PC, von Mutius E, Braun441 Fahrländer C, GABRIELA study group. 2011. The protective effect of farm milk consumption 
442 on childhood asthma and atopy: the GABRIELA study. Journal of Allergy and Clinical

443 Immunology 128:766-773.

444 Martín R, Langa S, Reviriego C, Jiménez E, Marín ML, Xaus J, Rodríguez JM. 2003.

445 Human milk is a source of lactic acid bacteria for the infant gut. Journal of Pediatrics

$446 \quad 143: 754-758$.

447 Mazzini E, Massimiliano L, Penna G, Rescigno M. 2014. Oral tolerance can be established 448 via gap junction transfer of fed antigens from CX3CR1+ macrophages to CD103+ dendritic 449 cells. Immunity 40: 248-261.

450 Miller RH, Paape MJ, Fulton LA. 1991. Variation in milk somatic cells of heifers at first 451 calving. Journal of Dairy Science $74:$ 3782-90.

452 Mutius E, Vercelli D. 2010. Farm living: effects on childhood asthma and allergy. Nature 453 Reviews in Immunology 10:861-868.

454 Pérez PF, Doré J, Leclerc M, Levenez F, Benyacoub J, Serrant P, Segura-Roggero I, 455 Schiffrin EJ, Donnet-Hughes A. 2007. Bacterial imprinting of the neonatal immune system: 456 lessons from maternal cells? Pediatrics 119:e724-e732.

457 Perkin MR, Strachan DP. 2006. Which aspects of the farming lifestyle explain the inverse 458 association with childhood allergy? Journal of Allergy and Clinical Immunology 117: 13744591381.

460 Press Release: US Representative Massie Introduces Bipartisan Milk Freedom Legislation, 461 2014. http://massie.house.gov/press-release/press-release-us-representative-massie462 introduces-bipartisan-milk-freedom-legislation.

463 Randolph GJ, Inaba K, Robbiani DF, Steinman RM, Muller WA. 1999. Differentiation of 464 phagocytic monocytes into lymph node dendritic cells in vivo. Immunity 11: 753-761. 
465 R Core Team 2013. R: A language and environment for statistical computing. R

466 Foundation for Statistical Computing, Vienna, Austria. URL http://www.R-project.org/).

467 Riedler J, Braun-Fahrländer C, Eder W, Schreuer M, Waser M, Maisch S, Carr D, Schierl

468 R, Nowak D. 2001. Exposure to farming in early life and development of asthma and allergy:

469 a cross-sectional survey. Lancet 358:1129-1133.

470 Riollet C, Rainard P, Poutrel B. 2000. Cells and cytokines in inflammatory secretions of

471 bovine mammary gland. Advances in Experimental Medicine and Biology 480: 247-258.

472 Rodríguez JM. 2014. The origin of human milk bacteria: is there a bacterial entero-

473 mammary pathway during late pregnancy and lactation? Advances in Nutrition 5: 779-784.

474 Roux ME, McWilliams M, Phillips-Quagliata JM, Weisz-Carrington P, Lamm ME.1977.

475 Origin of IgA-secreting plasma cells in the mammary gland. Journal of Experimental Medicine 476 146: 1311-1322.

477 Suzuki MT, Taylor LT, DeLong EF. 2000. Quantitative analysis of small-subunit rRNA 478 genes in mixed microbial populations via 5'-nuclease assays. Applied and Environmental 479 Microbiology 66: 4605-4614.

480 Vangroenweghe F, Dosogne H, Mehrzad J, Burvenich C. 2001. Effect of milk sampling 481 techniques on milk composition, bacterial contamination, viability and functions of resident 482 cells in milk. Veterinary Research 32: 565-579.

483 Waser M, Michels KB, Bieli C, Floistrup H, Pershagen G, von Mutius E, Ege M, Riedler J, 484 Schram-Bijkerk D, Brunekreef B, van Hage M, Lauener R, Braun-Fahrländer C; PARSIFAL 485 Study team. 2007. Inverse association of farm milk consumption with asthma and allergy in 486 rural and suburban populations across Europe. Clinical and Experimental Allergy 37:661-670.

487 Waser M, Schierl R, von Mutius E, Maisch S, Carr D, Riedler J, Eder W, Schreuer M, 488 Nowak D, Braun-Fahrländer C. 2004. Determinants of endotoxin levels in living environments 
489 of farmers' children and their peers from rural areas. Clinical and Experimental Allergy

$490 \quad 34: 389-397$.

491 Weisz-Carrington P, Roux ME, McWilliams M, Phillips-Quagliata JM, Lamm ME. 1979.

492 Organ and isotype distribution of plasma cells producing specific antibody after oral 493 immunization. Journal of Immunology 123:1705-1708. 
1

Analysis of diversity within communities.

Curves indicate Chaol index, a measure of community diversity, at each sampling depth, as shown on the X-axis. Error bars indicate SEM.

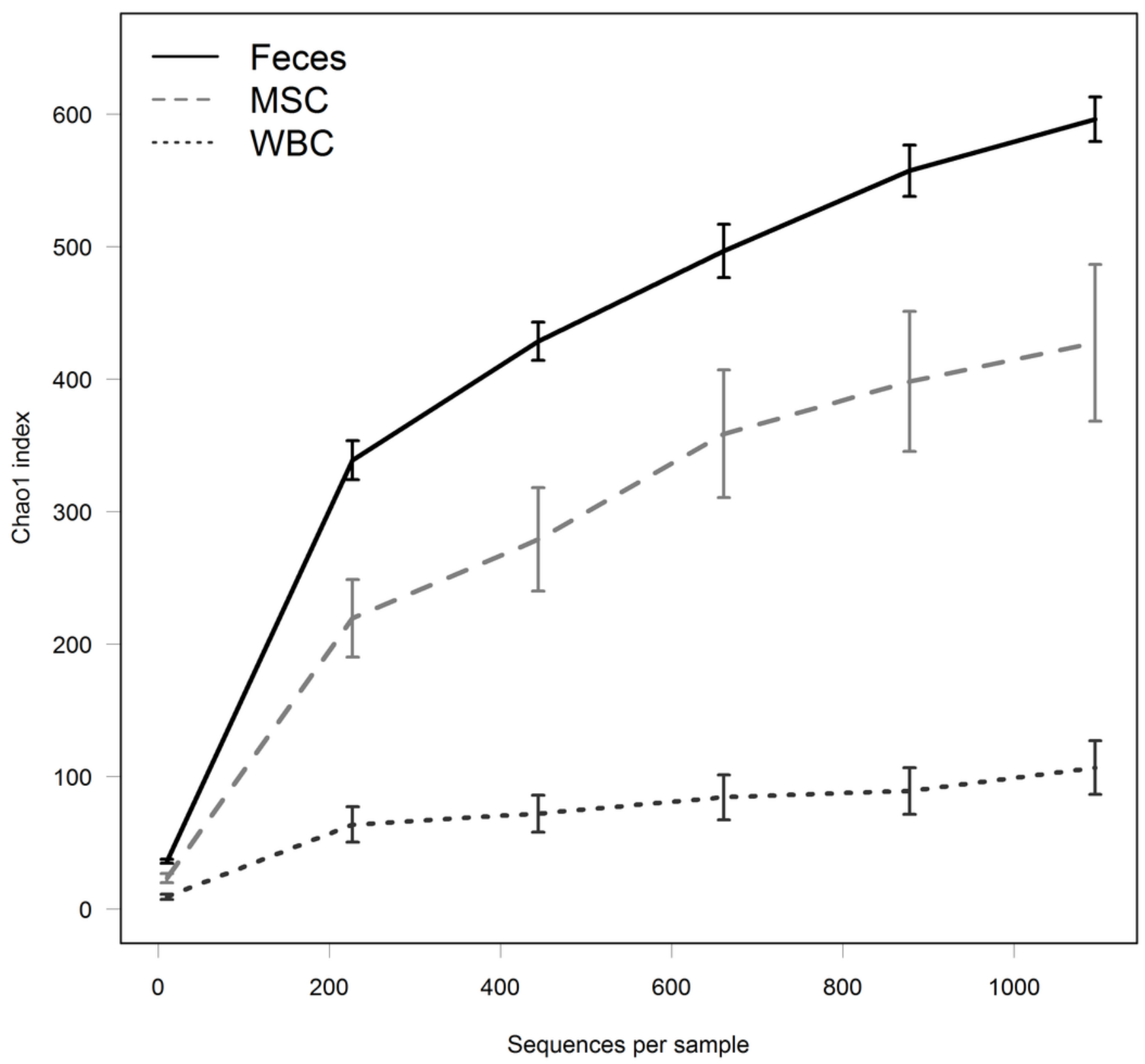


2

Cluster analysis of bacterial composition at genus level

Heatmap showing hierarchical clustering of analysis of bacterial composition profiles for the 50 most abundant genus level taxa as a proportion of total sequences for each sample.

Coloured bar beneath upper dendrogram indicates sample environment; fecal (yellow), milk cell (blue), white blood cell (red). Taxa are indicated by row labels and individual animal and sample environment indicated by column labels; F (fecal), M (milk cell), B (white blood cell), and numbers representing animal identification. Heatmap colour (blue to dark red) signify relative prevalence of each taxa across samples and green circles show absolute proportions for each taxa within a sample, with circle size proportional to sequence abundance. 


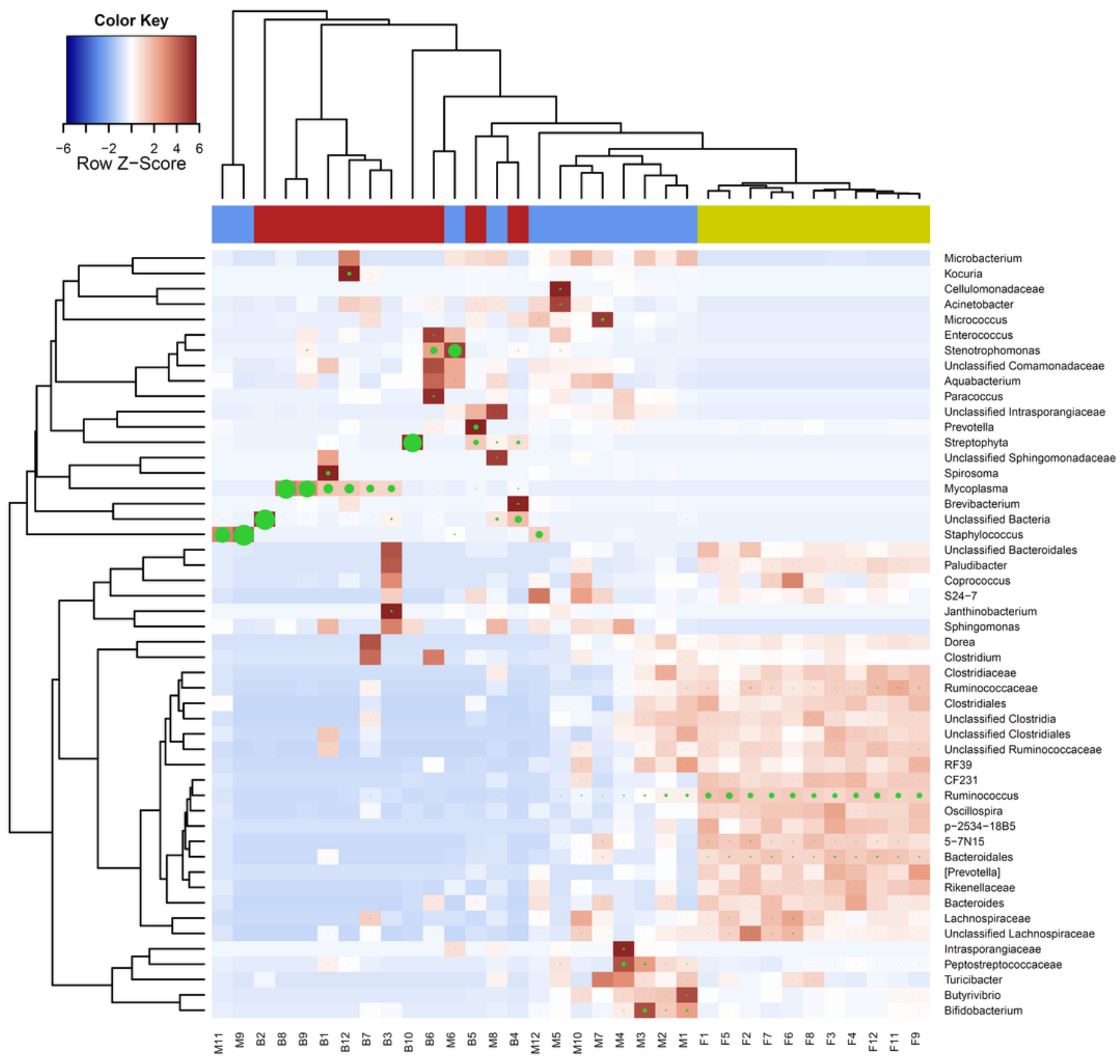


Bar chart of bacterial composition at family level.

Stacked bar chart of the 100 most abundant family level taxa found in each of the faecal $(n=11)$, milk cell $(n=12)$, and white blood cell $(n=11)$ environments. Bars show mean bacterial proportions for each environment.

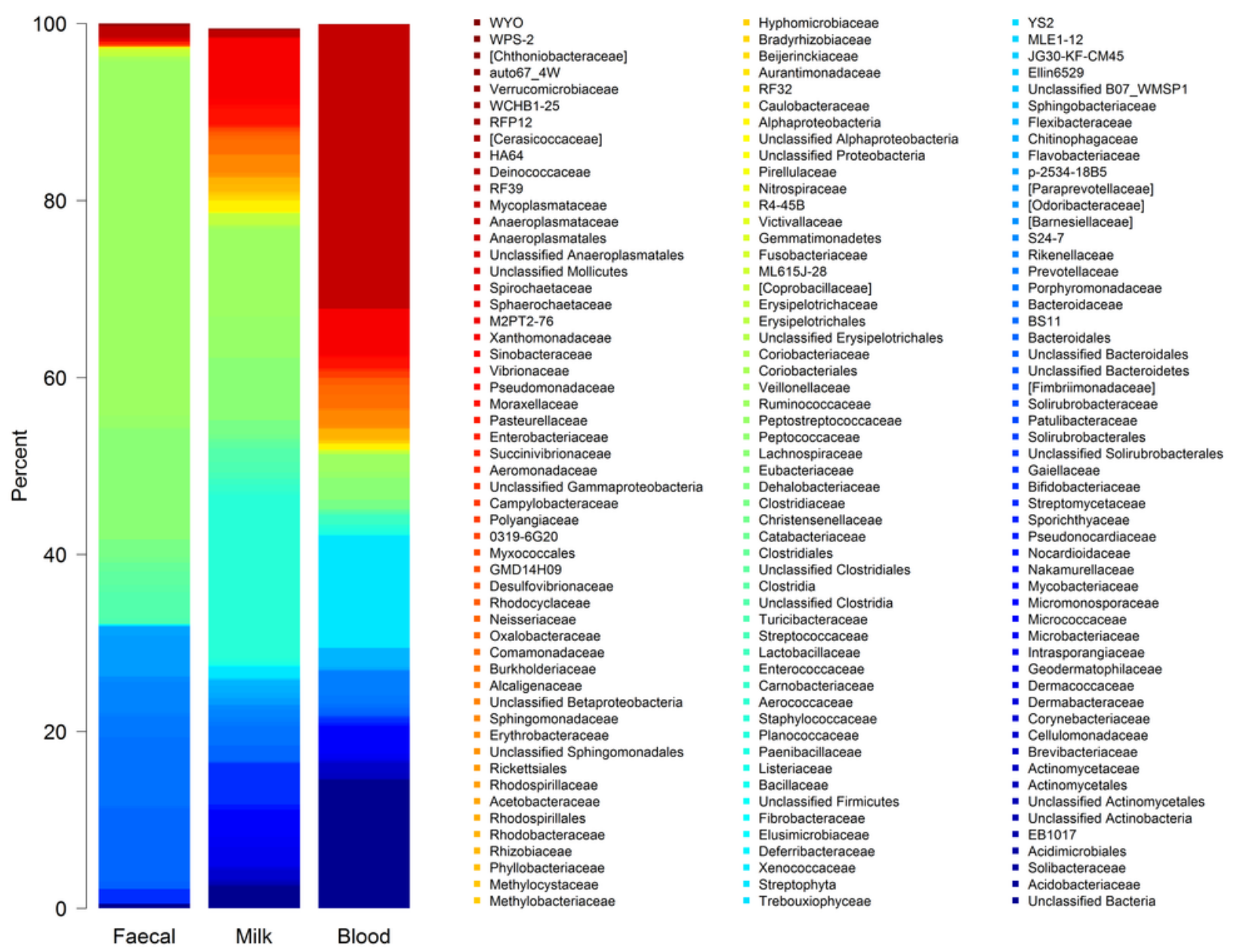


Figure $\mathbf{4}$ (on next page)

OTU network

OTU network linking samples and OTUs found in each sample. Samplestypes indicated by coloured shapes; fecal (yellow circle), milk cell (bluesquare), and white blood cell (red diamond). OTUs are shown by white dots and lines join OTU with sample which that OTU is found in. Lines are coloured according to sample type the OTUs are found in; fecal (yellow), milk cell (blue) and, white blood cell (red). Network arranged using a perfuse force directed layout where samples that share more OTUs are placed closer together. 


\section{PeerJ Reviewing Manuscript}

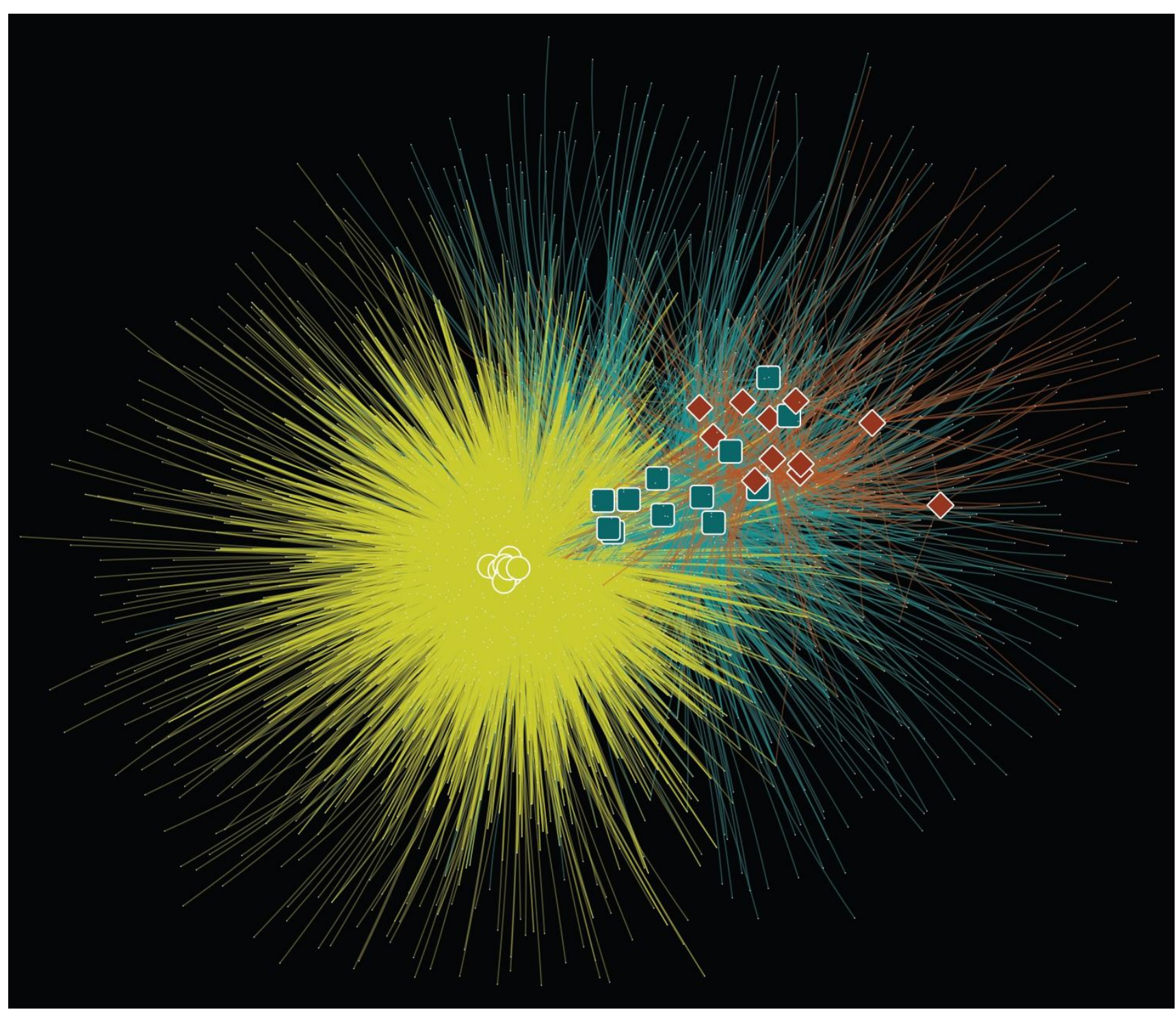




\section{Table $\mathbf{1}$ (on next page)}

Bacterial OTUs (bacterial signatures) found in the three biological samples from one or more sampled animal.

Profiling was performed by pyrosequencing of bacterial DNA. 
PeerJ Reviewing Manuscript

\begin{tabular}{|c|c|c|c|}
\hline OTU ID & Phylum & Classification & Animal ID \\
\hline 1759, 851, 1942 & Firmicutes & Ruminococcus & $3,5,7,9,12$ \\
\hline 251,1805 & Firmicutes & Peptostreptococcaceae & $1,5,7,8,12$ \\
\hline 2052 & Actinobacteria & Bifidobacterium & $3,5,7,8$ \\
\hline $1954,980,1511,883$ & Firmicutes & Lachnospiraceae & $3,5,7$ \\
\hline 119,792 & Firmicutes & Ruminococcaceae & $1,2,7$ \\
\hline 187,259 & Bacteroidetes & Bacteroidales & 3,5 \\
\hline 813 & Bacteroidetes & Paludibacter & 3,5 \\
\hline 476,478 & Firmicutes & Sarcina & 5,12 \\
\hline 1681 & Actinobacteria & Agrococcus jenensis & 5 \\
\hline 2183 & Actinobacteria & Microbacterium & 8 \\
\hline 1151 & Actinobacteria & Nakamurellaceae & 8 \\
\hline 589 & Bacteroidetes & Bacteroidaceae 5-7N15 & 5 \\
\hline 1188 & Bacteroidetes & Parabacteroides & 1 \\
\hline 2149 & Bacteroidetes & Bacteroidales S24-7 & 3 \\
\hline 67 & Cyanobacteria & Streptophyta & 12 \\
\hline 939 & Firmicutes & Blautia & 7 \\
\hline 1983 & Firmicutes & Clostridia & 7 \\
\hline 1533 & Firmicutes & Clostridiaceae & 7 \\
\hline 1219 & Firmicutes & Coprococcus & 12 \\
\hline 1053 & Firmicutes & Turicibacter & 2 \\
\hline 806 & Planctomycetes & Pirellulaceae & 5 \\
\hline 1369 & Proteobacteria & Agrobacterium & 3 \\
\hline 1834 & Proteobacteria & Escherichia & 7 \\
\hline 238 & Tenericutes & Mollicutes RF39 & 5 \\
\hline
\end{tabular}


Table 2 (on next page)

Abundance of bacterial taxa.

Profiling was performed by pyrosequencing of bacterial DNA. Taxonimic names listed correspond to the highest level identified ( 0.8 confidence) for each group of bacterial sequences detected. Phylum indicated by letter in parentheses: $F=$ Firmicutes, $B=$ Bacteroidetes, $\mathrm{T}=$ Tenericutes, $\mathrm{C}=$ Cyanobacteria, $\mathrm{P}=$ Proteobacteria, $\mathrm{A}=$ Actinobacteria. 


\begin{tabular}{|c|c|c|c|}
\hline Rank & Feces & White blood cells & Milk somatic cells \\
\hline 1 & (F) Ruminococcus (28.6\%) & (T) Mycoplasma (33.9\%) & (F) Staphylococcus (27.6\%) \\
\hline 2 & (B) Bacteroidales (8.2\%) & (C) Streptophyta (24.1\%) & (F) Ruminococcus (7.2\%) \\
\hline 3 & (F) Ruminococcaceae (6.5\%) & Unclassified bacteria (13.4\%) & (F) Peptostreptococcaceae (6.5\%) \\
\hline 4 & (B) Bacteroidaceae 5-7N15 (6.0\%) & (B) Prevotella (4.5\%) & (A) Bifidobacterium (5.6\%) \\
\hline 5 & (F) Unclassified Lachnospiraceae (4.0\%) & (P) Stenotrophomonas (3.3\%) & (F) Butyrivibrio (2.3\%) \\
\hline 6 & (F) Lachnospiraceae (3.8\%) & (P) Acinetobacter (1.1\%) & (P) Stenotrophomonas (2.1\%) \\
\hline 7 & (B) Paraprevotellaceae CF231 (3.5\%) & (A) Micrococcus (0.8\%) & (F) Ruminococcaceae (2.0\%) \\
\hline 8 & (B) Rikenellaceae (3.4\%) & (A) Kocuria $(0.7 \%)$ & (A) Intrasporangiaceae (1.8\%) \\
\hline
\end{tabular}

